\title{
Research utilization process model: A cyclical, spiral, and developmental process to provide conclusive research knowledge in health professions education
}

\author{
Tahereh Changiz ${ }^{* 1(\mathbb{D}}$, Alireza Yousefy $^{1}$, Mohammad Fakhari ${ }^{1}$ \\ Received: 7 Jul 2019 Published: 14 Jul 2020
}

\section{Abstract}

Background: Research utilization plays an important role in evidence-based practice. Health professions education is a researchbased discipline. Conclusive research knowledge is ranked as high level of evidence in evidence-based practice. This study was conducted to develop a model to reach conclusive research knowledge in health professions education.

Methods: This study was conducted in 2 phases. In the first phase, a qualitative content analysis of the literature was performed, which provided research utilization concepts to design a model. In the second phase, a group of 5 consultants of health professions education designed a preliminary model and revised it to develop an appropriate model for research utilization in health professions education.

Results: The indicators mentioned in 24 documents were extracted and later categorized into 25 items. Then, 8 concepts emerged, including problem identification, research design and implementation, research reports, research publication, presentation, research access, adoption, and research use. These concepts were arranged to design a model for research utilization in health professions education.

Conclusion: This study illustrated a cyclical, spiral, and developmental model to reach conclusive research knowledge. This model emphasizes both primary and secondary research projects to reach conclusive research knowledge. Also, it distinguishes between aligned transfer and cooperative presentation in research knowledge dissemination. This model reveals the importance of the process use in health profession education. Also, it distinguishes between use and misuse of research findings.

Keywords: Medical education, Utilization, Translational medical research, Diffusion of innovation

Conflicts of Interest: None declared

Funding: This study was performed by a grant from Isfahan University of Medical Sciences (project number: 394566).

\section{*This work has been published under CC BY-NC-SA 1.0 license. \\ Copyright $\odot$ Iran University of Medical Sciences}

Cite this article as: Changiz T, Yousefy A, Fakhari M. Research utilization process model: A cyclical, spiral, and developmental process to provide conclusive research knowledge in health professions education. Med J Islam Repub Iran. 2020 (14 Jul);34:79. https://doi.org/10.47176/mjiri.34.79

\section{Introduction}

In recent decades, efforts to base practices on the best evidence have attracted more attention to the utilizations

Corresponding author: Dr Tahereh Changiz, changiz@edc.mui.ac.ir

1. Department of Medical Education, Medical Education Research Center, Isfahan University of Medical Sciences, Isfahan, Iran of research findings in medical sciences (1). Studies must be conducted to fill the knowledge gap and overcome

$\uparrow$ What is "already known” in this topic:

Previous research utilization models have 3 main stages: production, transfer, and utilization of research findings. Previous models focused on instrumental utilization of research findings.

\section{$\rightarrow$ What this article adds:}

This study introduced a model to reach conclusive research knowledge in health professions education. It emphasized the process use of research in health professions education. This model distinguishes between researches for utilization from misuse of research. Also, it differentiates between aligned transfer and cooperative presentation in research knowledge dissemination. 
knowledge deficiencies in previous research (2). Distillation studies such as systematic reviews or meta-analysis researches should be conducted to integrate multiple research findings. Thus, multiple studies should be designed and conducted in a developmental process so that their findings could be integrated to reach conclusive research knowledge. Conclusive research knowledge should be used as the best evidence in the health profession education $(3,4)$.

Conclusive research knowledge is considered as the explicit type of knowledge in knowledge transfer and exchange (KTE). KTE plays an important role in institutional development. There are multiple models related to KTE and research utilization (5-7). These models have been designed to bridge the gap between research and practice. However, previous models have some shortcomings. KTE models have used each source of knowledge to transfer and exchange knowledge. These models did not consider the importance of conclusive research knowledge and assumed each research findings could be transferred and exchanged. These models defined a distillation phase to accumulate multiple research findings. The distillation of research findings is not defined as a research project and can be done by any research utilizer (5).

The health professions education is ranked as soft science and has its own research characteristics $(8,9)$. For instance, double-blinded, randomized and placebocontrolled trials as golden standard research could not easily be conducted in this field (10). Moreover, research training programs were conducted to train new researchers for other fields of research in health professions disciplines. Undergraduate research projects are one educational strategy in this educational curriculum (11). This study was conducted to develop a model to explain the research utilization process in health professions education.

\section{Methods}

This study was conducted in 2 phases. In the first phase, a systematized review and qualitative content analysis of the literature was performed. In this phase, literature review was conducted to extract research utilization-related concepts in recent health studies. These concepts create a basis for designing a model. In the second phase, an expert panel worked together to design a model for research utilization process.

In the first phase, the research utilization indicators were extracted from related documents published in English from 2000 to 2018. Google Scholar was used to access related documents (12). Search strategy included research utilization, dissemination or transfer, and determinants, factors or indicators, which were combined in the advanced search option. The retrieved document titles were reviewed for their relevance to the purpose of the study and unrelated documents were excluded. The selected documents were reviewed for the relevance of the abstracts to the purpose of the study, and unrelated documents were excluded. Then, the full-texts of the selected documents were reviewed and indicators for research utilization were extracted. Documents that did not refer to any indicators were excluded at this stage. At the end of the first phase, the indicators were entered into Microsoft Excel software 2010. Research utilization items and concepts were obtained thorough summative content analysis of indicators $(13,14)$. Similar items were grouped together, and duplicate items were merged with each other. Then, items were categorized in related groups as concepts.

In the second phase, a panel group worked together to design the research utilization model. Five consultants of health professions education collaborated to design the model. At this phase, the concepts obtained from the first phase were arranged in the logical process and illustrated connections between these concepts in a primary model. Then, the primary designed model was revised based on previous introduced models in health sciences (5-7). This preliminary model was repeatedly revised by the consultants. This model was presented to a large group of health professions education researchers and policymakers. The expert panel revised the preliminary model based on the comments of the large group.

\section{Results}

A total of 1310 documents were found in the initial literature search. After reviewing the title and abstracts, only 24 documents were selected for full-text review. Table 1 lists the characteristics of these documents. There has not been any study on the utilization of research findings in health professions education, and most of the documents were related to nursing. Also, most previous studies used survey as research methods.

The qualitative content analysis of these articles led to the extraction of research utilization-related items. The items were entered into Excel software and categorized into extracted concept by inductive methods. Table 2 refers to the label of extracted items and concepts, which were arranged based on the research utilization process. Therefore, the concept arrangement begins by creating research knowledge by conducting a study and is then directed towards knowledge dissemination, and finally to research knowledge utilization.

The expert panels arranged the concepts in the logical process and revised them based on previous models to develop a model for the research utilization process in health professions education (Fig. 1). This model was revised repeatedly and included 3 stages: knowledge production, dissemination, and utilization.

This model distinguishes between nonconclusive research findings utilizers and conclusive research knowledge utilizers. Researchers are the main utilizers of nonconclusive research findings to conduct new research project, while policymakers and educational practitioners are considered as conclusive research knowledge utilizers. This model emphasizes that conclusive research knowledge is the best research evidence for decisionmaking and practice improvement. Conclusive research knowledge produces a final output of this cyclical, spiral, and developmental process. This model consists of 3 stages with separation lines (gaps) among them. These stages include research knowledge production, research 
Table 1. Characteristics of the documents reviewed in this study, sorted based on year of publication, discipline, research design, and number of indicators

\begin{tabular}{|c|c|c|c|c|c|}
\hline First author & $\begin{array}{c}\text { Publication } \\
\text { year }\end{array}$ & Discipline & Research design & $\begin{array}{l}\text { Number of } \\
\text { indicators }\end{array}$ & $\begin{array}{c}\text { References } \\
\text { number }\end{array}$ \\
\hline Fernandez & 2016 & Obstetrics and gynecology & survey & 4 & $(15)$ \\
\hline Yoder & 2014 & Nursing & Survey & 5 & (16) \\
\hline Squires & 2014 & Nursing & Psychometric of tool & 5 & (17) \\
\hline Ruzafa Martinez & 2013 & Nursing & $\begin{array}{l}\text { Researcher made questionnaire } \\
\text { Psychometric of this }\end{array}$ & 24 & (18) \\
\hline Pitout & 2013 & Occupational therapists & Survey & 22 & (19) \\
\hline Groth & 2013 & Hand therapists & Survey & 8 & (20) \\
\hline Squires & 2011 & Nursing & Psychometric of tool & 5 & (21) \\
\hline Kothari & 2011 & Policy-makers & Focus group for indicator identification & 62 & $(22)$ \\
\hline Estabrooks & 2011 & Nursing & Focus group for indicator identification & 40 & (23) \\
\hline $\begin{array}{l}\text { Valdehueza- } \\
\text { Mahilum }\end{array}$ & 2010 & Art \& Science faculties & $\begin{array}{l}\text { Descriptive study by researcher-made } \\
\text { questionnaire }\end{array}$ & 40 & (24) \\
\hline Rice & 2010 & Social workers & Confirmatory factor analysis study & 25 & $(25)$ \\
\hline Featlver & 2010 & Higher education faculties & Survey questionnaire. & 14 & (26) \\
\hline Devos & 2007 & Industries & Psychometric of tool & 7 & (27) \\
\hline Bostorm & 2006 & Nursing & Survey & 25 & $(28)$ \\
\hline Milner & 2005 & Nurse & Survey & 4 & (29) \\
\hline & & & Regression for prediction factors & & \\
\hline Veeramah & 2004 & Graduate nurses and midwives & Survey & 27 & (30) \\
\hline Wallin & 2003 & Nursing & Survey & 20 & (31) \\
\hline Mccleary & 2003 & Nursing & Survey & 6 & (32) \\
\hline Landry & 2003 & Public administrators & Survey & 22 & (33) \\
\hline Kuuppelomäki & 2003 & Nursing & Survey & 39 & (34) \\
\hline Mccleary & 2002 & Nursing \& pediatric health & Survey & 21 & (35) \\
\hline Jolley & 2002 & Nursing & Survey & 9 & (36) \\
\hline Landry & 2001 & Nursing & Survey & 5 & (37) \\
\hline Clifford & 2001 & Nursing & Pre- and post-test evaluation & 18 & $(38)$ \\
\hline
\end{tabular}

Table 2. Extracted items and concepts in the qualitative content analysis phase. Research utilization concepts are arranged from research production to research utilization

\begin{tabular}{|c|c|c|c|}
\hline Research utilization stage & Research utilization concepts & Research utilization items & References of documents \\
\hline \multirow[t]{8}{*}{$\begin{array}{l}\text { Research knowledge } \\
\text { production }\end{array}$} & Problem identification & $\begin{array}{l}\text { Questioning of current practices } \\
\text { Gap identification }\end{array}$ & $\begin{array}{c}(19.23,25) \\
(25)\end{array}$ \\
\hline & \multirow[t]{4}{*}{$\begin{array}{l}\text { Research design \& } \\
\text { implementation }\end{array}$} & $\begin{array}{l}\text { Research question } \\
\text { formation }\end{array}$ & $(19,25)$ \\
\hline & & Research proposal & $(24,33,37,39)$ \\
\hline & & Proposal review & \\
\hline & & Research conduct & $(15,19,24,33,34,38)$ \\
\hline & \multirow[t]{3}{*}{ Research reports } & Research findings report & $(26,31,39)$ \\
\hline & & Research reports distillation & $(24,28,34,36)$ \\
\hline & & Archive & $(28,31,34)$ \\
\hline \multirow{5}{*}{$\begin{array}{l}\text { Research knowledge } \\
\text { dissemination }\end{array}$} & \multirow[t]{3}{*}{ Research publication } & Tailoring & $(22,33,37)$ \\
\hline & & Translate & $(30,34,38)$ \\
\hline & & Transfer & $(28,34)$ \\
\hline & \multirow[t]{2}{*}{ Presentation } & Presentation & $(15,19,22,23,24,25,26,39)$ \\
\hline & & Attendance & $(15,39)$ \\
\hline \multirow{9}{*}{$\begin{array}{l}\text { Research knowledge } \\
\text { utilization }\end{array}$} & \multirow[t]{3}{*}{ Research Access } & Search strategy formation & (18) \\
\hline & & Seek & $(18,19,20,25,30,32,39)$ \\
\hline & & Find & $(33)$ \\
\hline & \multirow[t]{3}{*}{ Adoption } & Read & $(15,19,23,24,28,31,32,33,39)$ \\
\hline & & Appraisal & $(18,20,23,24,25,26,28,30,31,32,33,34,36,38)$ \\
\hline & & Accept & $(23,29,34)$ \\
\hline & \multirow[t]{3}{*}{ Research use } & Instrumental use (Trial) & $\begin{array}{c}(16,18,19,20,23,24,25,26,28,29,30,31,32,33,3 \\
4,35,36,38)\end{array}$ \\
\hline & & Conceptual use & $(17,18,19,21,23,24,29,35)$ \\
\hline & & Process use (Research training) & $(22,28,31,33,38,39)$ \\
\hline
\end{tabular}

knowledge dissemination, and research knowledge utilization. This model explains 4 main gaps in research knowledge production to utilization process. There are 3 gaps among each stage and the diffusion gap in aligned transfer of research dissemination. These gaps could disrupt cyclical, spiral, and developmental process of research utilization.
The first stage of this model refers to production of research knowledge, which starts by problem identification. This model emphasizes problem identification based on previous research findings and literature review. Research should be designed and conducted to overcome knowledge deficit that had been identified in previous research utilization. Research knowledge is produced in 


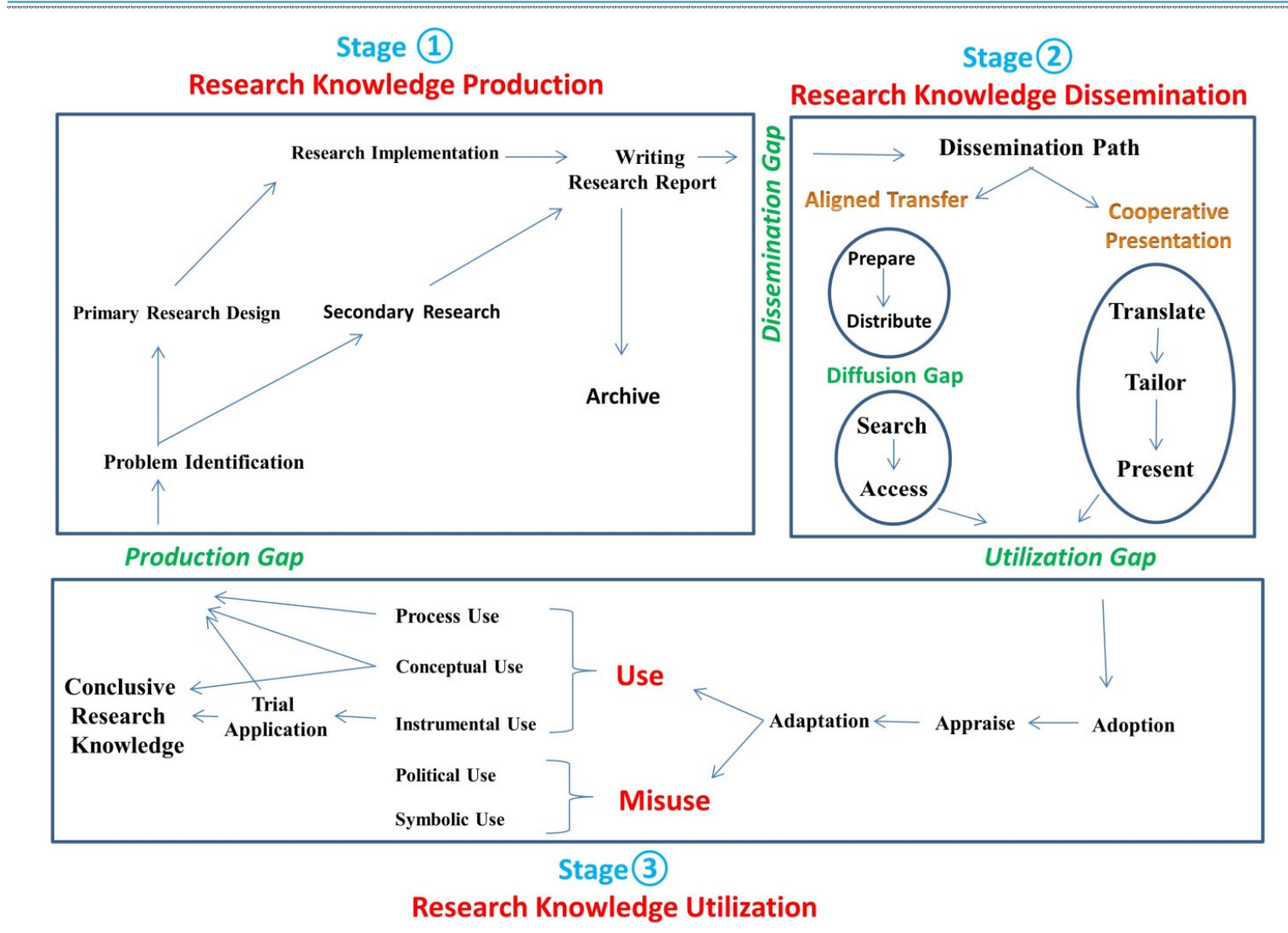

Fig. 1. Research utilization process model: A cyclical, spiral, and developmental process to provide conclusive research knowledge

primary and secondary research design. This model emphasizes the importance of secondary research in knowledge production in addition to primary research design. Secondary research project must design, conduct, disseminate, and utilize similar to primary research. Secondary research is performed to synthesize knowledge from multiple primary researches on a specific subject. To reach a conclusive knowledge on a specific subject, the research utilization process should be circulated in a spiral and developmental circle to produce multiple primary researches on a subject and integrate them.

The second stage of this model refers to dissemination of research findings to research utilizers. This model distinguished between aligned transfer and cooperative presentation. In the aligned transfer, researchers disseminate their research reports to unknown utilizers. Researchers do not have any predefined utilizers in this dissemination path. Researchers disseminate their research reports by publishing in scientific journals, broadcasting in scientific meeting or multimedia. In this path, research utilizers should search in databases and find published studies. There is a diffusion gap between publication research reports and utilizers' access to these reports. Some research reports maybe not published in an accessible format. Organizational facilities such as research databases and library decrease this gap.

Cooperative presentation is another path for research dissemination. Research findings are presented to predefined research utilizers. Researchers actively participate in the presentation of their research findings to predefined utilizers. In this path, the report of the research findings should be prepared for the utilizers in an understandable language called translation of reports. The research report must be prepared to address users' needs, which is called tailoring of reports. Then, the reports must be presented to them in an interactive meeting, called interactive presentation of reports.

The third stage of this model refers to the utilization of research findings. At this stage, research utilizers should use research, which is called adoption of research findings. Researches utilizers select suitable research findings by critically appraise research reports, which are called the appraisal of research findings. Ultimately, users may adapt research findings for utilization in a specific context, which is called adaptation of research findings.

This model distinguishes between research for utilization and misuse of research. Research utilization has 3 types: conceptual, instrumental, and process use. Conceptual use develops body of knowledge and provides new ideas for other researchers. The conceptual research use reveals research knowledge gap and creates a ground for developing new research questions. Instrumental use is related to application of recommended instruments or interventions to improve practice. The recommended instruments or interventions should be used in small groups as a trial application. In trial application, unapproved instruments or interventions should be studied in next research projects. This process continues until producing instruments or interventions for routine practice-approved instruments or intervention, which is considered as the 
conclusive research knowledge or guidelines. Another type of research utilization is the process use. It refers to learning by theories in health professions education. Each research improves its competencies during the research projects. In the process use of research, expert researchers may engage novice researchers in a research project to train them. Undergraduate research project is another example for process use of research. Undergraduate research projects are valuable educational experiences for novice researchers.

Misuse of research refers to the political or symbolic use of research. In the political utilization of research, utilizers select intended research findings and omitted or ignored unintended research findings to justify their decisions. The symbolic use of research occurs when researchers decorate their research by citation of previous research to gain prestige or personal benefit. The misuse of research disrupts cyclical, spiral, and developmental process of research utilization.

\section{Discussion}

The research utilization model was introduced to explain research utilization process in health professions education. This model defined a cyclical, spiral, and developmental process for research knowledge utilization. It considered both primary and secondary research in the production of conclusive research knowledge in the health professions education. Secondary research is one of the most important research projects distillations of research findings. Multiple types of secondary research design have been introduced in the literature (40). Educational researches are affected by multiple variables, and thus distillation of research findings is difficult in this field (9). Recently, due to the importance of secondary research in the health professions education, the Best Evidence in Medical education (BEME) and AMEE guides have been published (8). This model emphasized that the distillation of research findings should be defined as specific research project and be conducted by expert researchers. Previous models pay less attention to the importance of secondary research in research knowledge production. The knowledge translation model did not consider the secondary research design as a specific research project (6). Also, the knowledge to action model embedded a step named as distillation step to extract applicable research results from selected research (5). The knowledge to action model defined distillation as the final step of knowledge production to reach applicable tools or interventions. Distillation was not defined as a research project in the knowledge to action model.

In the second stage of this model, 2 paths were separated for research dissemination; however, previous models did not clearly distinguish between them. Previous researches mostly focused on aligned transfer in research dissemination. The knowledge to action model and the knowledge translation cycle defined transfer as a single step in research utilization $(5,6)$. The knowledge translation cycle hyperestimated the translation steps in research transfer. In previous models, such as knowledge translation cycle, the translation step became a larger concept than utilization and covered all aspects of research utilization. Majdzadeh et al considered aligned transfer and proposed some strategies to enhance research publication and access (6). The diffusion gap in the aligned transfer path could make this path ineffective for research dissemination.

The interactive path of research dissemination is a more effective path to research dissemination. Translation and tailoring of research report based on utilizer's language and their needs are explained in the most of knowledge transfer and exchange documents. Previous studies emphasized the characteristics of cooperative presentation as suitable strategies in research dissemination (41). A prerequisite for the interactive path is a predefined utilizer for research findings. Utilizers should be defined at the beginning of research design. The cooperative presentation of research reports is more important in this path. Continual interaction between presenter and audiences are necessary for translation and tailoring of research report. Also, the continual interaction may facilitate research adoption and critical appraisal steps in research utilization stage. Translation and tailoring of research report may be accomplished by trained persons also known as brokers (42).

The third stage of this model related to the research utilization. Previous models pointed to adaptation of research findings. The adoption and appraisal of research findings have an important role in convincing research utilizers to use research findings.

The final step in research utilization stage is research use. The conceptual utilization may be a more prevalent type of research use in health professions education. It is developing and expanding the body of knowledge in this field (43). However, previous models for research utilization paid less attention to these types of research utilization.

The process use is another important type of research utilization in the health profession education. Researchers develop their own unique research competencies during their research projects. Health professions education is a specific field of education that develops formal curriculums and educational courses to train researchers and utilizers (44). The process utilization of research is supported by previous learning models and based on the Dreyfus model of skill acquisition. The Dreyfus model describes how novice researchers progress to expert researchers through conduction of real research projects (45). Also, the involvement of research utilizers in research knowledge production can familiarize utilizers with the research process and change their attitude towards research (46).

The instrumental use of research was explained in previous model. Some models focused on the instrumental use of research specifically (5-7). This model emphasized the utilization of conclusive research knowledge as the best evidence for decision-making in knowledge-based organizations. This model focused on achieving conclusive research knowledge thorough cyclical, spiral, and developmental process of research utilization. Findings of single primary or secondary research study may not be assumed as conclusive research knowledge, and previous 
models paid less attention to this matter.

This model distinguished between use and misuse of research. The symbolic and political uses of research knowledge may be seen in organizational decision-making (47). This model categorizes the symbolic and political use of research findings as misuse of research findings The misuse of research disrupts cyclical, spiral, and developmental process of research utilization. Previous studies have allocated misuse of research as pseudo use of research. Stufflebeam and Coryn demonstrate 5 types of pseudo use of research in educational settings (48). Incidence of misuse is very difficult to detect due to ethical limitations. The symbolic use of research is often seen in self-citation and authorship misconduct $(49,50)$. The political use may be observed more frequently than instrumental use (51).

This model has some limitations. It could not explain all determinants and factors that affect research utilization process. Previous articles published on research utilization in health sciences have pointed to these determinants and factors $(52,53)$. Also, this model was limited to demonstrate the impact of the participants in the research utilization process. An effective collaboration among researchers, brokers, audience, receivers, and utilizers are necessary in the process of research utilization.

\section{Conclusion}

This study designed a cyclical, spiral, and developmental model for research production to utilization in the health professions education. This model emphasizes both primary and secondary research projects to reach conclusive research knowledge. Also, it distinguishes between aligned transfer and cooperative presentation in research knowledge dissemination. Moreover, this model reveals the importance of 3 types of research use (conceptual, instrumental, and process use) in the health professions education. The process use of research is an important use of research in health professions education, which distinguished between research use and misuse of research. In addition, it distinguishes between nonconclusive research knowledge utilizers and conclusive research knowledge utilizers. Researchers utilize nonconclusive previous research findings to conduct new research projects. This model demonstrates 3 main gaps between each stage and a gap in dissemination stage, which affects the cyclical process. Future research is needed to confirm this model and explore these relationships. Also, the model may be revised as more evidence becomes available.

\section{Acknowledgments}

This study was performed by a grant from Isfahan University of Medical Sciences (project number: 394566). The authors are grateful to all consultants who contributed to this study.

\section{Conflict of Interests}

The authors declare that they have no competing interests.

\section{References}

1.Dauphinee WD, Wood-Dauphinee S. The need for evidence in medical education: the development of best evidence medical education as an opportunity to inform, guide, and sustain medical education research. Acad Med. 2004;79(10):925-30.

2. Dechartres A, Ravaud P. Better prioritization to increase research value and decrease waste. BMC Med. 2015;13(1):244.

3. Ion G, Stîngu M, Marin E. How can researchers facilitate the utilisation of research by policy-makers and practitioners in education? Res Pap Educ. 2018;34(4):483-498.

4. Uzochukwu B, Onwujekwe O, Mbachu C, Okwuosa C, Etiaba E, Nyström ME, et al. The challenge of bridging the gap between researchers and policy makers: experiences of a Health Policy Research Group in engaging policy makers to support evidence informed policy making in Nigeria. Glob Health. 2016;12(1):67.

5. Graham ID, Logan J, Harrison MB, Straus SE, Tetroe J, Caswell W, et al. Lost in knowledge translation: time for a map?J Contin Educ Health Prof. 2006;26(1):13-24.

6. Majdzadeh R, Sadighi J, Nejat S, Mahani AS, Gholami J. Knowledge translation for research utilization: design of a knowledge translation model at Tehran University of Medical Sciences. J Contin Educ Health Prof. 2008;28(4):270-7.

7. Stetler CB. Updating the Stetler model of research utilization to facilitate evidence-based practice. Nurs Outlook. 2001;49(6):272-9.

8. Patrício M, vaz Carneiro A. Systematic reviews of evidence in medical education and clinical medicine: Is the nature of evidence similar? Med Teach. 2012;34(6):474-82.

9. Gruppen LD. Is medical education research 'hard'or 'soft'research? Adv in Health Sci Educ. 2008;13:1-2.

10. Kaptchuk TJ. The double-blind, randomized, placebo-controlled trial: gold standard or golden calf? J Clin Epidemiol. 2001;54(6):5419.

11. Linn MC, Palmer E, Baranger A, Gerard E, Stone E. Undergraduate research experiences: Impacts and opportunities. Science. 2015;347(6222):

12. Jean-François G, Laetitia R, Stefan D. Is the coverage of Google Scholar enough to be used alone for systematic reviews. BMC Med Inform. 2013;13(1):1.

13. Hsieh HF, Shannon SE. Three approaches to qualitative content analysis. Qual Health Res. 2005;15(9):1277-88.

14. Bengtsson M. How to plan and perform a qualitative study using content analysis. Nurs Plus Open. 2016;2:8-14.

15. Fernandez A, Sadownik L, Lisonkova S, Cundiff G, Joseph K. Determinants of research engagement in academic obstetrics and gynaecology. BMC Med Educ. 2016;16(1):111.

16. Yoder LH, Kirkley D, McFall DC, Kirksey KM, StalBaum AL, Sellers D. CE: Original Research: Staff nurses' use of research to facilitate evidence-based practice. Am J Nurs. 2014;114(9):26-37.

17. Squires JE, Estabrooks CA, Hayduk L, Gierl M, Newburn-Cook CV. Precision of the conceptual research utilization scale. J Nurs Measur. 2014;22(1):145-63.

18. Ruzafa-Martinez M, Lopez-Iborra L, Moreno-Casbas T, MadrigalTorres M. Development and validation of the competence in evidence based practice questionnaire (EBP-COQ) among nursing students. BMC Med Educ. 2013;13(1):1.

19. Pitout H. Research orientation of South African occupational therapists. South African J Occup Ther.. 2013;43(2):05-11.

20. Groth GN, Farrar-Edwards D. Patterns of research utilization among Certified Hand Therapists. J Hand Ther. 2013;26(3):245-54.

21. Squires JE, Estabrooks CA, Newburn-Cook CV, Gierl M. Validation of the conceptual research utilization scale: an application of the standards for educational and psychological testing in healthcare. BMC Health Serv Res. 2011;11(1):1.

22. Kothari A, MacLean L, Edwards N, Hobbs A. Indicators at the interface: managing policymaker-researcher collaboration. Know Manag Res Pract. 2011;9(3):203-14.

23. Estabrooks CA, Squires JE, Strandberg E, Nilsson-Kajermo K, Scott SD, Profetto-McGrath J, et al. Towards better measures of research utilization: a collaborative study in Canada and Sweden. J Adv Nurs. 2011;67(8):1705-18

24. Valdehueza-Mahilum J. Determinants of research involvement, dissemination and utilization among the arts and sciences faculty in Southern Philippines. Liceo J High Edu Res. 2010;6(2).

25. Rice K, Hwang J, Abrefa-Gyan T, Powell K. Evidence-Based Practice Questionnaire: A confirmatory factor analysis in a social 
work sample. Adv Soc Work. 2010;11(2):158-73.

26. Featlver M. Predictors of research dissemination and utilization in State Higher Education Institutions in Region IV, Philippines. Liceo J High Edu Res. 2010;6(2): 336-348

27. Devos C, Dumay X, Bonami M, Bates R, Holton E. The Learning Transfer System Inventory (LTSI) translated into French: internal structure and predictive validity. Int J Train Dev. 2007;11(3):181-99.

28. Boström AM, Wallin L, Nordström G. Research use in the care of older people: a survey among healthcare staff. Int J Older People Nurs. 2006;1(3):131-40.

29. Milner FM, Estabrooks C, Humphrey C. Clinical nurse educators as agents for change: increasing research utilization. Int J Nurs Stud. 2005;42(8):899-914.

30. Veeramah V. Utilization of research findings by graduate nurses and midwives. J Adv Nurs. 2004;47(2):183-91.

31. Wallin L, Boström AM, Wikblad K, Ewald U. Sustainability in changing clinical practice promotes evidence-based nursing care. J Adv Nurs. 2003;41(5):509-18.

32. McCleary L, Brown GT. Association between nurses' education about research and their research use. Nurse Educ Today. 2003;23(8):556-65.

33. Landry R, Lamari M, Amara N. Extent and determinants of utilization of university research in public administration. Public Adm Rev. 2003;63(2):191-204.

34. Kuuppelomäki M, Tuomi J. Finnish nurses' views on their research activities. J Clin Nurs. 2003;12(4):589-600.

35. McCleary L, Brown TG. Use of the Edmonton research orientation scale with nurses. J Nurs Measur. 2002;10(3):263-75.

36. Jolley S. Raising research awareness: a strategy for nurses. Nurs Standard. 2002;16(33):33-9.

37. Landry R, Amara N, Lamari M. Climbing the ladder of research utilization evidence from social science research. Sci Commun. 2001;22(4):396-422.

38. Clifford C, Murray S. Pre-and post-test evaluation of a project to facilitate research development in practice in a hospital setting. J Adv Nurs. 2001;36(5):685-95.

39. McCleary L, Brown GT. Research utilization among pediatric health professionals. Nurs Health Sci. 2002;4(4):163-71.

40. Grant MJ, Booth A. A typology of reviews: an analysis of 14 review types and associated methodologies. Health Info Libr J. 2009;26(2):91-108.

41. Siron S, Dagenais C, Ridde V. What research tells us about knowledge transfer strategies to improve public health in low-income countries: a scoping review. Int J Public Health. 2015;60(7):849-63.

42. Ward VL, House AO, Hamer S. Knowledge brokering: Exploring the process of transferring knowledge into action. BMC Health Serv. Res. 2009;9(1):12.

43. Vleuten CP. Medical education research: a vibrant community of research and education practice. Med Educ. 2014;48(8):761-7.

44. Norman G. Fifty years of medical education research: waves of migration. Med Educ. 2011;45(8):785-91.

45. Dreyfus SE. The five-stage model of adult skill acquisition. Bullet Sci Technol Soc. 2004;24(3):177-81.

46. Ismail MA, Kareem SA. Identifying how novice researchers search, locate, choose and use web resources at the early stage of research. Malaysian J Libr Inf Sci. 2011;16(3):67-85.

47. Sandberg J, Persson B, Garpenby P. The dilemma of knowledge use in political decision-making: National Guidelines in a Swedish priority-setting context. Health Econ Policy Law. 2018:1-18.

48. Stufflebeam DL, Coryn CL. Evaluation theory, models, and applications. 2nd ed: Jossey-Bass; 2014.pp.117-132

49. Ioannidis JP. A generalized view of self-citation: Direct, co-author, collaborative, and coercive induced self-citation. J Psychosom Res. 2015;78(1):7-11.

50. Yousefy A, Fakhari M. A comparative study on authorship trends in four Persian and English Journals in the field of Medical Education. Int J Educ Psychol Res. 2016;2(4):224.

51. Ferguson L. External validity, generalizability, and knowledge utilization. J Nurs Scholarsh. 2004;36(1):16-22.

52. Meijers JMM, Janssen MAP, Cummings GG, Wallin L, Estabrooks CA, Halfens RYG. Assessing the relationships between contextual factors and research utilization in nursing: systematic literature review. J Adv Nurs. 2006;55(5):622-35.

53. Squires JE, Estabrooks CA, Gustavsson P, Wallin L. Individual determinants of research utilization by nurses: a systematic review 